\title{
Potential of Pseudomonas chlororaphis subsp. aurantiaca Strain Pcho10 as a Biocontrol Agent Against Fusarium graminearum
}

\author{
Weiqun Hu, Qixun Gao, Mohamed Sobhy Hamada, Dawood Hosni Dawood, \\ Jingwu Zheng, Yun Chen, and Zhonghua Ma
}

First, second, third, fifth, sixth, and seventh authors: Institute of Biotechnology, Zhejiang University, Hangzhou, 310058, China; third author: Pesticides Department, Faculty of Agriculture, Mansoura University, Mansoura, 35516, Egypt; and fourth author: Department of Chemistry, Zhejiang University, Hangzhou 310028, China and Department of Agriculture Chemistry, Faculty of Agriculture, Mansoura University, Mansoura 35516, Egypt. Accepted for publication 11 June 2014.

\begin{abstract}
Hu, W., Gao, Q., Hamada, M. S., Dawood, D. H., Zheng, J., Chen, Y., and Ma, Z. 2014. Potential of Pseudomonas chlororaphis subsp. aurantiaca strain Pcho10 as a biocontrol agent against Fusarium graminearum. Phytopathology 104:1289-1297.

To develop an effective biocontrol strategy for management of Fusarium head blight on wheat caused by Fusarium graminearum, the bacterial biocontrol agent Pcho10 was selected from more than 1,476 wheat-head-associated bacterial strains according to its antagonistic activity in vitro. This strain was subsequently characterized as Pseudomonas chlororaphis subsp. aurantiaca based on 16S ribosomal DNA sequence analysis, assays of the BIOLOG microbial identification

produced by Pcho10 was further identified as phenazine-1-carboxamide (PCN) on the basis of nuclear magnetic resonance data. The core PCN biosynthesis gene cluster in Pcho10 was cloned and sequenced. PCN showed strong inhibitory activity against $F$. graminearum conidial germination, mycelial growth, and deoxynivalenol production. Tests both under growth chamber conditions and in field trials showed that Pcho10 well colonized on the wheat head and effectively controlled the disease caused by $F$. graminearum. Results of this study indicate that $P$. chlororaphis subsp. aurantiaca Pcho10 has high potential to be developed as a biocontrol agent against $F$. graminearum. To our knowledge, this is the first report of the use of $P$. chlororaphis for the management of Fusarium head blight.
\end{abstract} system, and unique pigment production. The major antifungal metabolite
The filamentous ascomycete Fusarium graminearum (teleomorph: Gibberella zeae) is the main causal agent of Fusarium head blight (FHB) in small-grain cereals. The incidence of FHB has increased worldwide, as shown by the recent outbreaks in the United States, Canada, Europe, and Asia $(18,35,42,54)$. In China, FHB has become a serious threat to wheat production since the year 2000, particularly in the middle and downstream regions of the Yangtze River and in the northeastern region $(5,29,59)$. In addition to the severe yield losses caused by FHB, mycotoxins such as deoxynivalenol (DON) and zearalenone produced by $F$. graminearum in infected grains also pose a threat to human and animal health $(25,36,45)$. Despite the considerable economic impact of FHB, no efficient and effective strategies for the management of FHB are available. In general, the development of resistant varieties is considered one of the most practical and environmentally safe methods of controlling plant diseases. For FHB, because of the fact that the identified resistant sources are only partially effective and major quantitative trait locus (QTL)based (51), FHB-resistant varieties are still not available (58). In addition, although some azole fungicides are moderately effective, spray coverage and the timing of application present difficulties (12). Moreover, the intensive application of fungicides can lead to the emergence of fungal strains that are resistant to the commercial chemicals $(30,59)$. Furthermore, application of some fungicides may stimulate the fungus to produce more mycotoxins

Corresponding author: Y. Chen; E-mail address: chenyun0927@zju.edu.cn

* The $\boldsymbol{e}$-Xtra logo stands for "electronic extra" and indicates that the online version contains two supplemental figures. Figures 1 to 5 appear in color online.

http://dx.doi.org/10.1094/PHYTO-02-14-0049-R

(C) 2014 The American Phytopathological Society
(14). The above limitations have prompted us to explore safer and more environmentally friendly biological control measures for $F$. graminearum as alternatives.

Various microorganisms, including Trichoderma spp., yeasts, and bacteria, have been tested for their effectiveness in the biological control of FHB (17). Among these biocontrol agents, several genera of bacteria, in particular Bacillus $(15,50)$ and Streptomyces (41), have shown significant effects against fungal growth and mycotoxin production under laboratory conditions and in field trials $(20,39,49)$. In particular, antibiotics and antifungal compounds, such as lipopeptides iturin and fengycin produced by Bacillus spp., inhibit pathogen growth and reduce mycotoxin production and accumulation in the cereal hosts $(4,11$, 56). Several strains of Pseudomonas fluorescens have also been used successfully to control FHB symptoms caused by $F$. culmorum (26). Because bacterial biocontrol agents have shown considerable potential for FHB disease control, they have received the most attention in terms of suitability for being considered for commercial application (9).

In this study, we screened a highly effective biocontrol agent (Pcho10) against $F$. graminearum in vitro, in a growth chamber, and in field trials, and identified the antifungal compounds produced by this biocontrol strain.

\section{MATERIALS AND METHODS}

Bacterial and fungal strains. The $F$. graminearum strain $\mathrm{PH}-1$, originally isolated from corn in Michigan, was deposited in the Fungal Genetics Stock Center (Kansas City, MO) under accession number NRRL 31084. The biocontrol agent Pcho10, isolated from a wheat head, was deposited to the China General Microbiological Culture Collection Center under accession num- 
ber CGMCC 7729. All pathogens used in this study were provided by the Institute of Biotechnology, Zhejiang University (Hangzhou, China).

Screening of antagonistic strains in vitro. Bacterial isolates were recovered from Fusarium spp.-infested wheat heads in Jiangsu and Anhui provinces by using dilution plating methods (1). Briefly, each sample was homogenized with a sterilized mortar and pestle. Macerated samples were serially diluted with sterile $0.85 \% \mathrm{NaCl}$ solution, and resulting suspensions were plated onto Luria-Bertani (LB) agar. Single colonies were randomly picked according to colony morphology from plates after $48 \mathrm{~h}$ of incubation at $30^{\circ} \mathrm{C}$ and stored at $-70^{\circ} \mathrm{C}$ for further investigation.

Primary screening for antifungal activity of the wheat-headassociated bacterial strains against nine phytopathogenic fungi (F. graminearum, F. oxysporum f. sp. radicis-lycopersici, Magnaporthe oryzae, Rhizoctonia cerealis, $R$. solani, Botrytis cinerea, Phytophthora capsici, Bipolaris maydis, and Rhizopus stolonifer) were conducted on Waksman's agar (WA) (5 g of peptone, $10 \mathrm{~g}$ of glucose, $3 \mathrm{~g}$ of beef extract, $5 \mathrm{~g}$ of $\mathrm{NaCl}$, and $15 \mathrm{~g}$ of agar, made up to 1 liter, $\mathrm{pH} 7.2$ ). All isolates were tested in triplicate. After plates were incubated at $25^{\circ} \mathrm{C}$ for growth, the inhibition zone of each bacterial isolate was examined until the colony of target fungal pathogen in the control extended to more than two-thirds of the plate.

Identification of the antagonistic strain Pcho10. The Pcho10 strain was identified by using $16 \mathrm{~S}$ ribosomal DNA (rDNA) sequence, the BIOLOG Microbial Identification System, and pigment phenotype. For bacterial $16 \mathrm{~S}$ ribosomal DNA (rDNA) sequence, bacterial genomic DNA was extracted using the Bacterial Genomic DNA Extraction Kit (TaKaRa Biotechnology Co., Ltd.). The $16 \mathrm{~S}$ rDNA fragment was amplified by polymerase chain reaction (PCR) with the primer pair fD1/rP2 (57) (Table 1). The PCR products were purified and sequenced by BGI Co. (Shenzhen, China).The 16S rDNA sequence of Pcho10 was subjected to BLAST in the National Center for Biotechnology Information (NCBI) Database. Phylogenetic analyses with $16 \mathrm{~S}$ rDNA sequence were conducted using the neighbor-joining method with Molecular Evolutionary Genetics Analysis, version 4.0 (53). The phenotypic identification of Pcho10 was conducted by using BIOLOG (Biolog Inc., California) according to the instructions of the manufacturer. For pigment phenotype assay, Pcho10 was grown in King's B (KB) medium (10 g of peptone, $1.5 \mathrm{~g}$ of $\mathrm{K}_{2} \mathrm{HPO}_{4}, 15 \mathrm{~g}$ of glycerol, and $5 \mathrm{ml}$ of $1 \mathrm{M} \mathrm{MgSO}_{4}, \mathrm{pH}$ 7.2) for $48 \mathrm{~h}$, and the resulting cell suspension was then transferred to 24-well plates and cultured statically for pigment examination.

The antagonistic activity of Pcho10 strain against $F$. graminearum. Inhibition of mycelial growth towards $F$. graminearum by Pcho10 was tested in vitro on WA plates. Briefly, a $0.5-\mathrm{cm}$ plug taken from the edge of a 3-day-old colony of $F$. graminearum PH-1 was placed in the center of a WA plate. Two 5- $\mu \mathrm{l}$ aliquots of cell suspension of Pcho10 grown in KB broth for $24 \mathrm{~h}$ were spotted on opposite sides, $2.5 \mathrm{~cm}$ away from the center of the fungal plug in the plate. A nonantagonistic Pseudomonas fluorescens C9 was used as the negative control. After the plates were incubated at $25^{\circ} \mathrm{C}$ for 4 days, the inhibition zone was examined. The experiment was repeated four times independently.

To determine the minimum inhibitory concentration (MIC) of the Pcho10 toward F. graminearum mycelium in vitro, the 3-dayold cell suspension of Pcho10 was added to molten WA medium $\left(45^{\circ} \mathrm{C}\right)$ to produce the following concentrations: $10^{8}, 10^{7}, 10^{6}, 10^{5}$, and $10^{4} \mathrm{CFU} / \mathrm{ml}$. A single 5-mm mycelial plug taken from the edge of a 3-day-old colony of PH-1was placed onto the center of a potato dextrose agar (PDA) plate amended with Pcho10 cells at each of the above concentrations. Three replicates were used for each concentration. After 4 days of incubation at $25^{\circ} \mathrm{C}$, the colony diameter in each plate was measured in two perpendicular directions, with the original mycelia plug diameter $(5 \mathrm{~mm})$ subtracted from this measurement. The experiment was performed three times independently.

Characterization of antifungal compounds produced by Pch10. Pcho10 were grown in $\mathrm{KB}$ broth at $30^{\circ} \mathrm{C}$ for 3 days in a shaker $(200 \mathrm{rpm})$. Cells were removed after 3 days of incubation by centrifugation at $10,000 \times g$. The resultant supernatant $(1.5$ liters) was concentrated using a rotary evaporator and then extracted three times with ethyl acetate $(3 \times, 200 \mathrm{ml})$. Then, the crude ethyl acetate extracts $(1 \mathrm{~g})$ were obtained after evaporation and subjected to silica gel column chromatography (CC) (200 to 300 meshes). Extracts were eluted with $\mathrm{CHCl}_{3}$ followed by the combination of $\mathrm{CHCl}_{3}: \mathrm{MeOH}$ ranging from 99:1 to $0: 100$. The antagonistic activity of each fraction was tested against $F$. graminearum mycelium growth by agar well diffusion assay. For the assay, WA plates containing $F$. graminearum $\mathrm{PH}-1$ at $10^{5}$ conidia/ml of agar were prepared. Four plugs with the diameter of $5 \mathrm{~mm}$ were cut in the agar using a sterile cork-borer. A droplet of molten agar was added to each well in order to seal its bottom to avoid leakage. A 50- $\mu$ l aliquot of each eluted fraction was added into each well and pre-incubated at room temperature for $5 \mathrm{~h}$. After the plates were incubated at $25^{\circ} \mathrm{C}$ for $36 \mathrm{~h}$, inhibition zones around each well were examined.

Nuclear magnetic resonance spectroscopic data of extracts compounds were obtained on a Bruker Avance DRX-500 MHz spectrometer with TMS as an internal standard (chemical shifts $[\delta]$ were expressed in micrograms per milliliter concerning the solvent signals; sample was dissolved in $0.7 \mathrm{ml}$ of $\mathrm{CDCl}_{3}$ ). Accurate mass values were obtained on an Agilent Technologies

TABLE 1. Oligonucleotide primers used in this study

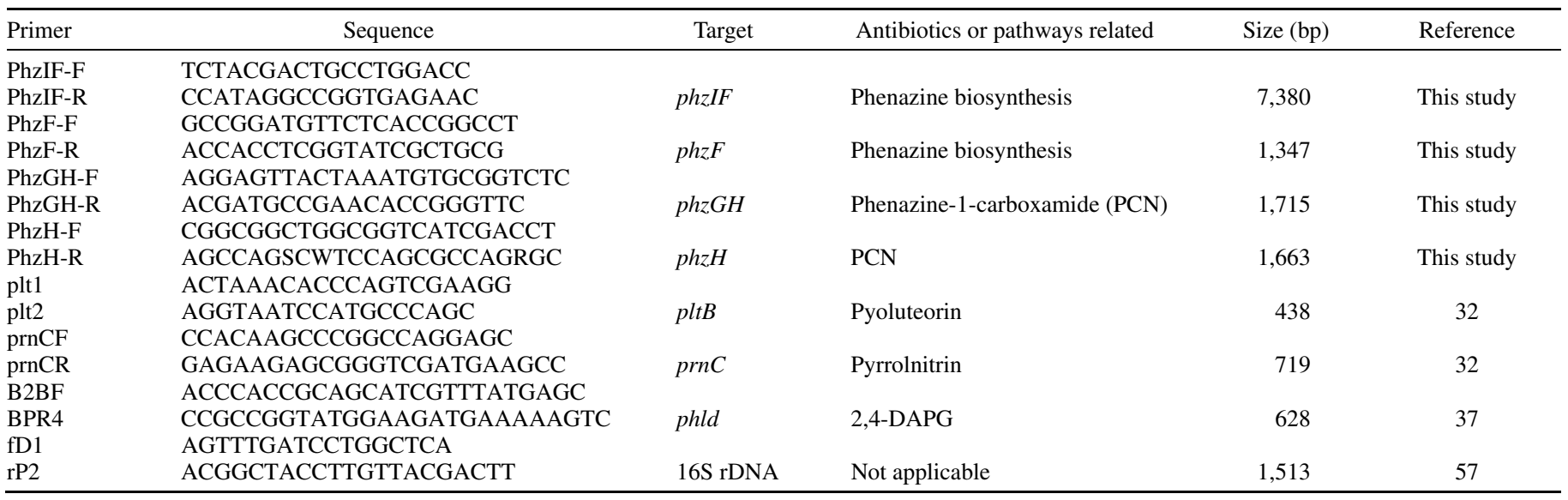


5975 inert Mass Selective Detector. CC was performed with 200to 300-mesh silica gel (Fisher Scientific, UK). Thin-layer chromatography (TLC) was carried out on preparative silica gel 60 F254 plates (Merck, Darmstadt, Germany), and spots were visualized by spraying with $5 \% \mathrm{H}_{2} \mathrm{SO}_{4}$ in $\mathrm{EtOH}$, then heating them at $105^{\circ} \mathrm{C}$

The antagonistic activity of Pcho10 strain cell-free supernatant and extracted compound against mycelia growth and conidial germination of $\boldsymbol{F}$. graminearum. The antagonistic activities of cell-free supernatant (CFS) of Pcho10 and extracted compound number 1 was evaluated by the above-described agar well diffusion assay. To prepare the cell-free supernatant, Pcho10 was grown in $\mathrm{KB}$ broth at $30^{\circ} \mathrm{C}$ in a shaker $(200 \mathrm{rpm})$. After 3 days of incubation, the supernatant of Pcho10 was collected and filtered through a $0.22-\mu \mathrm{m}$-pore-size hydrophilic membrane. The extracted compound number 1 was dissolved with methanol $(10 \mu \mathrm{g} / \mathrm{ml})$. A nonantagonistic P. fluorescens C9 and methanol served as the negative controls. The experiment was repeated three times independently.

Inhibition activities against conidial germination of $F$. graminearum were examined in $2 \%$ sucrose water solution amended with $1 \%$ CFS of Pcho10 (vol/vol) or compound number 1 at the final concentration of $10 \mu \mathrm{g} / \mathrm{ml}$. The same amounts of $P$. fluorescens C9 CFS and methanol were used as negative controls. The $\mathrm{PH}-1$ conidia were adjusted to $10^{4}$ conidia/ml using the hemocytometer. After conidial suspensions were incubated at $25^{\circ} \mathrm{C}$ for 4 , 8 , and $12 \mathrm{~h}$, the percentages of germinating conidia were examined under a phase-contrast microscope. At least 400 conidia were examined for each replication, and there were three replicates for each treatment. The experiment was repeated three times independently.

Activity of phenazine-1-carboxamide against $\boldsymbol{F}$. graminearum mycelia growth and DON production. To test the phenazine-1carboxamide (PCN) activity toward $F$. graminearum mycelia growth, a 5-mm mycelial plug was taken from the edge of the actively growing culture of $\mathrm{PH}-1$ strain and transferred onto the center of PDA plates containing PCN at $35 \mu \mathrm{g} / \mathrm{ml}$. Phenazine, 1-phenazine carboxylic acid (PCA), and 1-hydroxyphenazine (1-HP) produced by Pseudomonas spp. were used as control treatments. In addition, to determine the concentration for $50 \%$ of maximal effect $\left(\mathrm{EC}_{50}\right)$ of $\mathrm{PCN}$ against $F$. graminearum, a $5-\mathrm{mm}$ mycelial plug of each strain was transferred to a PDA agar plate amended with PCN at $1,5,10,15,20,25,30,40$, or $50 \mu \mathrm{g} / \mathrm{ml}$. The solvent chloroform was used as a negative control treatment. Three plates replicated plates were used for each concentration. Plates were then placed in an incubation chamber at $25^{\circ} \mathrm{C}$. When the PH-1 colony on the negative control plate extended to twothirds of the plate, mycelia growth on each plate was recorded. $\mathrm{EC}_{50}$ values were calculated with a computer program (Data Processing System; Hangzhou Reifeng Information Technology Ltd., Hangzhou, China). The experiment was repeated twice.

The hyphal morphology of PH-1 treated with PCN at $20 \mu \mathrm{g} / \mathrm{ml}$ was examined with a Leica TCS SP5 imaging system using fresh mycelia after $18 \mathrm{~h}$ of incubation at $25^{\circ} \mathrm{C}$ in potato dextrose broth in a shaker $(180 \mathrm{rpm})$. To test whether the PCN can inhibit the DON production of $F$. graminearum, we measured the DON production of wheat kernels treated with different concentrations of PCN. Briefly, a 50-g aliquot of healthy wheat kernels was autoclaved and then inoculated with eight mycelial plugs of PH-1. PCN was mixed with wheat kernels at final concentrations of 0.2 , $0.5,0.6,0.8$, and $1 \mathrm{mg} / \mathrm{g}$ of wheat kernels. The sterile water was added as a control. After incubation at $25^{\circ} \mathrm{C}$ for 20 days, DON was extracted using previously described protocols. The DON extracts were purified with PuriToxSR DON column TC-T200 (Trilogy Analytical Laboratory), and amounts of DON in each treatment were determined using a Waters 1525 high-performance liquid chromatography system (30). The experiment was repeated three times.
Cloning of the phenazine biosynthesis genes cluster in Pcho10. The gene sequence of the phenazine synthesis cluster ( $p h z I R A B C D E F G)$ and the downstream sequence $p h z H$ were determined by standard PCR from Pchol0 genomic DNA (oligonucleotide primers are shown in Table 1). The PCR products were purified and sequenced by BGI Co. Sequence similarities were analyzed by BLAST in the NCBI Database.

Efficacy of Pcho10 against FHB in a growth chamber. Biocontrol efficacy of Pcho10 against FHB in a growth chamber was conducted using two wheat cultivars, 'Yangmai 18' (moderate resistant to FHB) and 'Jimai 22' (susceptible to FHB). At midanthesis, wheat heads with $10-\mathrm{cm}$ stems were collected from the field. A single wheat head was set in a test tube filled with sterile water. Wheat spikes were sprayed with a cell suspension of biocontrol strain Pcho10 $\left(10^{8} \mathrm{CFU} / \mathrm{ml}\right)$ or control strain C9 $\left(10^{8}\right.$ $\mathrm{CFU} / \mathrm{ml}$ ) with a handheld atomizer until numerous droplets were deposited onto the wheat heads. In addition, cyanoacrylate fungicide JS399-19 (2 mg/ml) and only sterile water served as positive and negative controls, respectively. After droplets on wheat heads air dried for $6 \mathrm{~h}$ in a growth chamber, each treated wheat head was sprayed with a 3 -ml conidial suspension of $F$. graminearum strain $\mathrm{PH}-1$ at a concentration of $10^{4}$ conidia $/ \mathrm{ml}$ with $0.05 \%$ Tween 20 . The inoculated wheat heads were kept in the growth chamber at $25^{\circ} \mathrm{C}$ and $100 \%$ humidity with a 12-h photoperiod. For each treatment, 50 wheat heads were used. Seven days after inoculation, the percentage of infected spikelets in each wheat head was recorded. The experiment was repeated twice.

Efficacy of Pcho10 against FHB in field trials. Field experiments were conducted at Haian, Jiangsu Province and Hangzhou, Zhejiang Province in China during spring 2013 with Yangmai 18 and Jimai 22, respectively. The field trials were conducted using a randomized plot design, with three replicates of each treatment. Each plot was 4 by $5 \mathrm{~m}^{2}$ in size. Appropriate fertilizers and herbicides were applied according to standard management practices. Each plot was sprayed twice at 5 and $15 \%$ anthesis with $500 \mathrm{ml}$ of Pcho10 cell suspension at a concentration of $10^{8} \mathrm{CFU} / \mathrm{ml}$ amended with $0.05 \%$ Tween 20 . In addition, cell suspensions of strain C9 at a concentration of $10^{8} \mathrm{CFU} / \mathrm{ml}$ with $0.05 \%$ Tween 20 and cyanoacrylate fungicide JS399-19 $(2 \mathrm{mg} / \mathrm{ml})$ were used as negative and positive controls, respectively. At $24 \mathrm{~h}$ after the first time application of Pcho10, each plot was sprayed with $500 \mathrm{ml}$ of conidial suspension $\left(10^{4}\right.$ spores $\left./ \mathrm{ml}\right)$ of $F$. graminearum. All treatments were performed in the late afternoon before sunset. Twenty-five days after inoculation, FHB disease severity in each plot was examined. Disease index in wheat heads was assessed with five evaluation classes, classified according to codes 0 to 4 , which correspond to a percentage of wheat head surface showing FHB symptoms $(0=0,1=1$ to $25,2=26$ to 50 , $3=51$ to 75 , and $4=>75 \%$ ). Disease index (DI) of each plot was calculated using the formula $[(\Sigma$ number of wheat heads in each class $\times$ each evaluation class)/(total number of wheat heads $\times 4)] \times$ 100. Efficacy of each treatment was determined by applying Abbott's formula: [(DI of the negative control - DI of the treatment)/DI of the negative control)] $\times 100 \%$. The experiment was performed twice and the data were analyzed using Fisher's protected least significant difference test $(P=0.05)$ of SAS (SAS version 8.0; SAS Institute, Cary, NC).

Population dynamics of Pcho10 on wheat spikes. To monitor population levels of Pcho10 on wheat heads during the biocontrol assay, Pcho10 was labeled with rifampicin for recovery. During the biocontrol assay in the growth chamber, five wheat heads (Jimai 22) were collected each day in 1 week after treatment, pooled in a sample bag, and crushed in $10 \mathrm{ml}$ of sterile phosphate with a tissue homogenizer. To determine the CFU counts of the Pcho10, serial dilutions of the cell suspension were made and plated on LB medium supplemented with rifampicin $(100 \mu \mathrm{g} / \mathrm{ml})$. Cycloheximide $(100 \mu \mathrm{g} / \mathrm{ml})$ was added to all plates to prevent 
fungal growth. Four plates were used for each dilution. The plates were incubated at $30^{\circ} \mathrm{C}$ for 2 days before the number of colonies was counted. The colonization pattern of Pcho10 on the surface of spikes after 7 days of inoculation in the growth chamber was visualized with a Hitachi TM-1000 tabletop microscope (Hitachi, Tokyo).

Population of Pcho10 on wheat heads in the field was also quantified. At $0,1,3,7,13,20$, and 25 days after the second Pcho10 application, five wheat heads were randomly picked up for population determination in the field, as in the above method. Population levels of Pcho10 were expressed as $\log _{10}$ CFU per wheat spike.

Nucleotide sequence accession numbers. Nucleotide sequences of the $16 \mathrm{~S}$ rDNA and core phenazine biosynthesis gene cluster in P. chlororaphis Pcho10 were submitted to the GenBank database under accession numbers KF879088 and KJ457347.

\section{RESULTS}

Screening for antagonistic strains in vitro. Cultivable bacterial species were found very abundant in the Fusarium spp.infected wheat heads in Jiangsu and Anhui provinces, with population densities of $6.89 \times 10^{5}$ and $1.57 \times 10^{6}$ cells per gram fresh weight, respectively. In total, 1,476 bacterial isolates were selected and examined in terms of their antagonistic activities against $F$. graminearum, $F$. oxysporum, $M$. oryzae, Rhizoctonia cerealis, R. solani, Botrytis cinerea, Phytophthora capsici, Bipolaris maydis, and Rhizopus stolonifer using an in vitro assay (see Materials and Methods). Among them, 62 and 85 isolates obtained from Jiangsu and Anhui Provinces, respectively, showed various degrees of antagonism toward $F$. graminearum. Of these 147 isolates, 13 demonstrated very strong antagonistic activity, as shown by their formation of an $F$. graminearum inhibition zone $>10 \mathrm{~mm}$ in diameter in the in vitro assay (Table 2). We further characterized those bacterial species by performing the 16S rDNA sequencing. These 13 isolates were identified as Bacillus spp. $(n=8)$, Pseudomonas spp. $(n=4)$, and a Streptomyces sp. $(n=1)$.

The Pseudomonas sp. strain displaying the strongest antagonistic activity was selected for further investigation and designated Pcho10. Pcho10 displayed a strong inhibition against $F$. graminearum, F. oxysporum, and $M$. oryzae and, to a lesser extent against Rhizoctonia cerealis, $R$. solani, Botrytis cinerea, $P$. capsici, Bipolaris maydis, and Rhizopus stolonifer (Table 3; Fig. 1A) in in vitro assays. To further evaluate the antifungal activity of Pcho10 against $F$. graminearum in vitro, we determined the MIC of Pcho10 for $F$. graminearum mycelial growth. The radial growth of $F$. graminearum decreased significantly as the cell concentration of Pcho10 increased in WA medium (Fig. 1B). Pcho10 at a concentration of $10^{8} \mathrm{CFU} / \mathrm{ml}$ completely inhibited the mycelium growth of $F$. graminearum.

Identification of the antagonistic strain Pcho10 as Pseudomonas chlororaphis. A 1,402-bp PCR fragment was amplified with primers fD1/rP2, and showed $99 \%$ similarity to the $16 \mathrm{~S}$ ribosomal RNA (rRNA) sequence of Pseudomonas chlororaphis strain ATCC17411. Based on 16S rRNA sequences of Pcho10
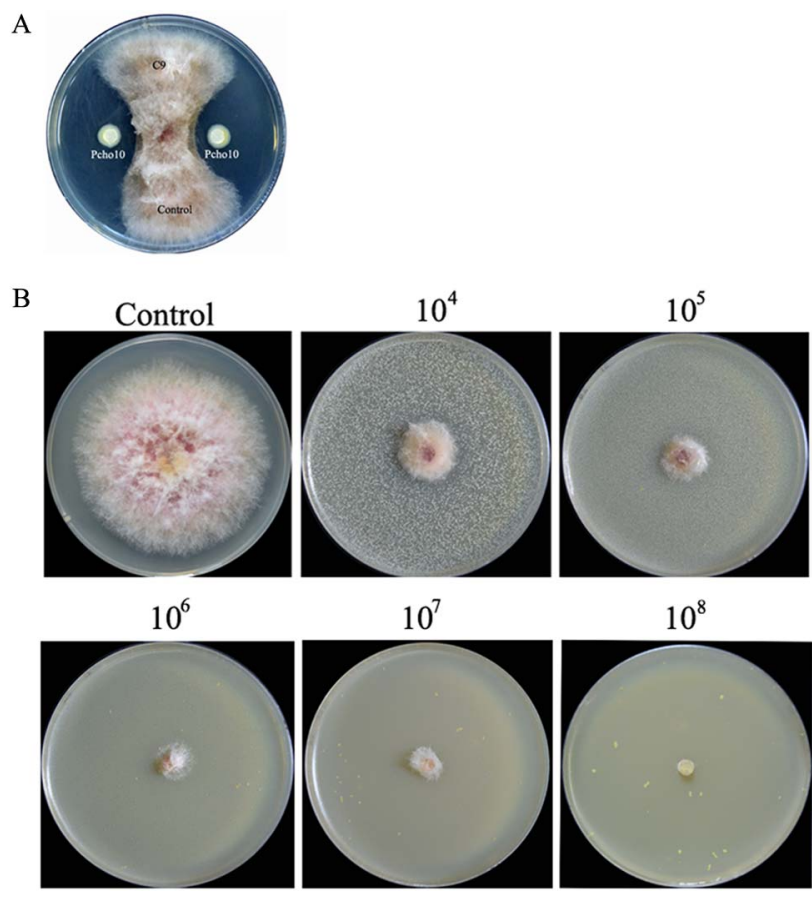

Fig. 1. Bioactivity of Pcho10 against Fusarium graminearum in vitro. A, Antagonistic activity of Pchol0 toward F. graminearum mycelia, with Pseudomonas fluorescens $\mathrm{C} 9$ and $\mathrm{H}_{2} \mathrm{O}$ treatments as negative controls. B, Inhibition of Pcho10 at serial concentrations against mycelial growth of $F$. graminearum on Waksman's agar (WA) plates. A WA plate without Pcho10 served as the control.

TABLE 2. Summary of screening results for antagonistic strains obtained from wheat-heads in the Jiangsu and Anhui Provinces

\begin{tabular}{|c|c|c|c|c|c|c|c|}
\hline \multirow[b]{2}{*}{ Local } & \multirow[b]{2}{*}{ Density $\left(\text { cells } \mathrm{g}^{-1} \mathrm{fw}\right)^{\mathrm{a}}$} & \multirow[b]{2}{*}{ Isolates tested } & \multicolumn{2}{|c|}{$\begin{array}{c}\text { Antagonistic toward } \\
\text { Fusarium graminearum }\end{array}$} & \multicolumn{3}{|c|}{$\begin{array}{c}\text { Radius of inhibition zone toward } \\
\text { F. graminearum }(\mathrm{mm})\end{array}$} \\
\hline & & & Number & Percent & $<5$ & $5-10$ & $>10$ \\
\hline Anhui Province & $6.89 \times 10^{5}$ & 670 & 62 & 9.25 & 26 & 31 & 5 \\
\hline Jiangsu Province & $1.57 \times 10^{6}$ & 806 & 85 & 10.55 & 42 & 35 & 8 \\
\hline
\end{tabular}

a Densities of bacteria on wheat head.

TABLE 3. Inhibition of phytopathogens by Pcho10 on agar plates in the dual-culture test

\begin{tabular}{|c|c|c|c|}
\hline Pathogen & Host & Disease & Radius of inhibition zone $(\mathrm{mm})(\mathrm{SE})^{\mathrm{a}}$ \\
\hline Fusarium graminearum & Wheat & Blight & $11.83 \pm 0.76$ \\
\hline F. oxysporum f. sp. radicis-lycopersici & Tomato & Wilt & $10.67 \pm 0.76$ \\
\hline Magnaporthe oryzae & Rice & Blast & $11.50 \pm 0.50$ \\
\hline Rhizoctonia cereal & Wheat & Leaf spot & $7.50 \pm 0.50$ \\
\hline Rhizoctonia solani & Wheat & Leaf spot & $8.50 \pm 0.50$ \\
\hline Botrytis cinerea & Strawberry & Blight & $4.93 \pm 0.12$ \\
\hline Phytophthora capsici & Pepper & Wilt & $4.33 \pm 0.58$ \\
\hline Bipolaris maydis & Corn & Leaf spot & $4.50 \pm 0.50$ \\
\hline Rhizopus stolonifer & Carrot & Rot & $8.17 \pm 0.29$ \\
\hline
\end{tabular}

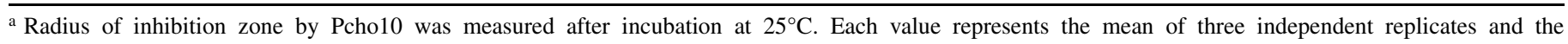
corresponding standard error (SE). 
and from the NCBI GenBank (GU947817, GCF_000281915, NR_044974, NR_102835, CP006832, NR_074834, CP000075, NR_102854, FJ405889, and NR_074599), we constructed the phylogenetic tree for Pcho10 and various sequenced Pseudomonas spp. (Fig. 2A). Our analysis indicated that the closest species to Pcho10 is $P$. chlororaphis subsp. aurantiaca (Fig. 2A). The BIOLOG system also recognized Pcho10 as $P$. chlororaphis subsp. aurantiaca, with a similarity index of 0.509 and a distance index of 7.286. Furthermore, Pcho10 produced both green and orange nonfluorescent pigments that were speculated to be PCN (chlororaphin) and phenazine-1-carboxylate compounds, respectively (Fig. 2B), characteristic secondary metabolites produced by various subspecies of $P$. chlororaphis (44). Taken together, these results indicate that Pcho10 is a strain of P. chlororaphis subsp. aurantiaca.

Characterization of the antifungal compound produced by Pcho10. Because Pcho10 CFS inhibited F. graminearum mycelial growth and conidia germination (Fig. 3), we identified the antifungal compounds produced by Pcho10. The CFS of Pcho10 cells was extracted using ethyl acetate, and the extract was subjected to a silica gel $\mathrm{CC}$ and eluted with various $\mathrm{CHCl}_{3}: \mathrm{MeOH}$ ratios. In total, 20 fractions were collected after elution. The bioactivity against $F$. graminnearum in vitro of each fraction was then evaluated. Fraction 2 eluted using $\mathrm{CHCl}_{3}: \mathrm{MeOH}(85: 15)$ displayed a high bioactivity against $F$. graminearum and showed a single spot using TLC (data not shown), indicating that this fraction contains a single compound. This compound was subjected to highresolution electrospray ionization mass spectrometry (ESI-MS) analysis, which yielded a peak at m/z 223.0745 [M] $]^{+}$. Analyses of the spectral data and comparison with compounds reported by Jayatilake (24) and Chin-A-Woeng (7) are shown in Table 4. In addition, the anhydrous compound number 1 was an acerose powder of green and golden yellow color. Therefore, compound number 1 was identified as PCN (Fig. 4A). PCN production by Pcho10 stain reached $\approx 200 \mathrm{mg} /$ liter after 3 days of incubation in $\mathrm{KB}$ broth.

PCN bioactivity toward $\boldsymbol{F}$. graminearum. In the bioactivity assay, compound number 1 (PCN) exhibited strong inhibition of F. graminearum mycelial growth (Fig. 3A) and totally suppressed conidial germination at a concentration of $10 \mu \mathrm{g} / \mathrm{ml}$ (Fig. 3B). Radial growth was severely inhibited on PDA containing PCN at

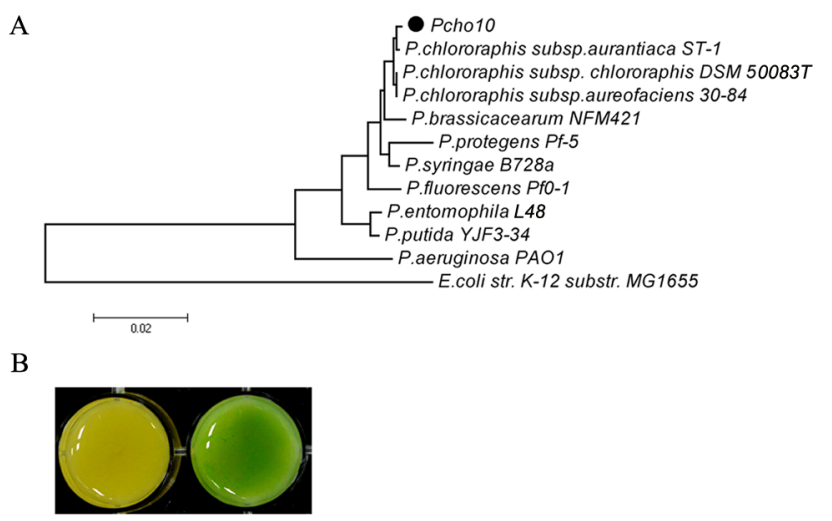

Fig. 2. Identification of the biocontrol agent Pcho10. A, Phylogenetic tree generated by the neighbor-joining method with the MEGA 4.1 software using the 16S rDNA sequences of Pcho10 and following Pseudomonas spp.: Pseudomonas chlororaphis subsp. aurantiaca ST-1(GU947817), P. chlororaphis subsp. aureofaciens 30-84 (GCF_000281915), P. chlororaphis subsp. chlororaphis DSM 50083T (NR_044974), P. fluorescens Pf0-1(NR_102835), $P$. aeruginosa PAO1 (CP006832), P. brassicacearum NFM421(NR_074834), P. syringae B728a (CP000075), P. entomophila L48 (NR_102854), P. putida YJF3-34 (FJ405889), and $P$. protegens Pf-5(NR_074599).The 16S rDNA sequence of Escherichia coli MG1655 (U00096.3) was used as an out-cluster control. B, Nonfluorescent pigments phenazine-1-carboxamide (chlororaphin) (green) and phenazine-1-carboxylate (orange) produced by Pcho10.
$35 \mu \mathrm{g} / \mathrm{ml}$ but not by PCA, 1-HP, or phenazine produced by Pseudomonas spp. (Fig. 4B). The $\mathrm{EC}_{50}$ value of PCN against $F$. graminearum was $7.283 \mu \mathrm{g} / \mathrm{ml}(Y=2.444 x+2.964, r=0.901)$. Mycelia were misshapen following PCN treatment (Fig. 4C). Meanwhile, DON production was significantly reduced with increasing PCN addition (Fig. 4D).

The highly conserved phenazine biosynthesis gene cluster in Pcho10. A 10,039-bp DNA fragment containing the putative phenazine biosynthesis gene cluster was amplified by PCR of Pcho10 samples using degenerate primers (see Materials and Methods for details) and sequenced. This DNA sequence was predicted to contain 10 open reading frames highly homologous with phenazine biosynthesis gene clusters from five other $P$. chlororaphis strains (Table 5; Fig. 4E). The core genes ( $p h z A$ to $p h z G)$ were highly conserved and were flanked by various auxiliary genes encoding phenazine-modifying enzymes and the regulatory proteins PhzI and PhzR in Pseudomonas spp. strains (Fig. 4E). Similar to P. chlororaphis PCL1391, Pcho10 contains the $p h z H$ gene but not the $p h z O$ gene, which was found to be located downstream of the core biosynthesis genes. The $p h z H$ gene encodes a putative transamidase that converts a portion of

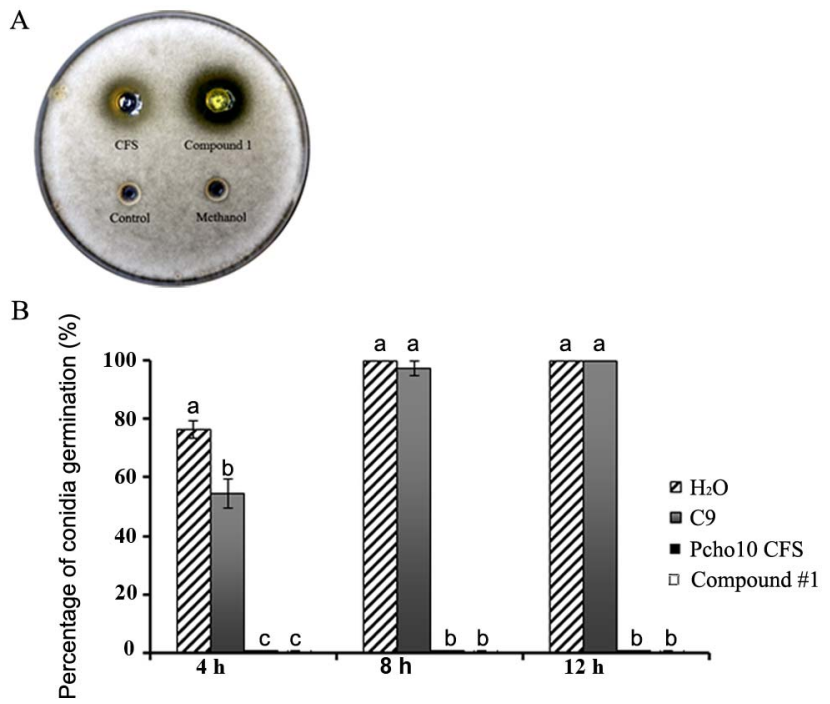

Fig. 3. Antagonistic activity of Pchol0 cell-free supernatant (CFS) and the compound number 1 (phenazine-1-carboxamide [PCN]) against Fusarium graminearum mycelial growth and conidial germination. A, Inhibition by the Pcho10 CFS and compound number 1 against $F$. graminearum on the potato dextrose agar plate supplemented with $F$. graminearum conidia after incubation at $25^{\circ} \mathrm{C}$ for $36 \mathrm{~h}$. B, Suppression of conidial germination after 4,8 , and $12 \mathrm{~h}$ of incubation with Pcho10 CFS or compound number 1 (PCN). C9 CFS and water served as negative controls. Columns with the same letters are not significantly different $(P=0.05)$.

TABLE 4. Nuclear magnetic resonance $(500 \mathrm{MHz})$ data for the compound number 1 produced by $\mathrm{Pcho} 10$ in $\mathrm{CDCl}_{3}$

\begin{tabular}{llll}
\hline Position & ${ }^{\delta} \mathrm{H}$, mult. $(\mathrm{J}$ in $\mathrm{Hz})$ & \multicolumn{1}{c}{$\mathrm{C}$, mult. } & HMBC $(\mathrm{H} \rightarrow \mathrm{C})$ \\
\hline 1 & $\ldots$ & $143.74, \mathrm{C}$ & $\mathrm{C}-3, \mathrm{C}-4 \mathrm{a}$ \\
2 & $8.43, \mathrm{~d}(8.5)$ & $134.57, \mathrm{CH}$ & $\mathrm{C}-4, \mathrm{C}-10$ \\
3 & $7.98, \mathrm{t}(7.5)$ & $130.14, \mathrm{CH}$ & $\mathrm{C}-1, \mathrm{C}-4 \mathrm{a}$ \\
4 & $9.02, \mathrm{~d}(7.5)$ & $136.20, \mathrm{CH}$ & $\mathrm{C}-2, \mathrm{C}-10$ \\
$4 \mathrm{a}$ & $\ldots$ & $129.13, \mathrm{C}$ & $\ldots$ \\
5 & $\ldots$ & $141.76, \mathrm{C}$ & $\ldots$ \\
6 & $8.23, \mathrm{dd}(2.5,6.0)$ & $129.35, \mathrm{CH}$ & $\mathrm{C}-8, \mathrm{C}-9 \mathrm{a}$ \\
7 & $7.92, \mathrm{~m}$ & $132.00, \mathrm{CH}$ & $\mathrm{C}-5, \mathrm{C}-9$ \\
8 & $7.92, \mathrm{~m}$ & $131.32, \mathrm{CH}$ & $\mathrm{C}-6, \mathrm{C}-9 \mathrm{a}$ \\
9 & $8.29, \mathrm{dd}(4.0,7.0)$ & $130.00, \mathrm{CH}$ & $\mathrm{C}-5, \mathrm{C}-7$ \\
$9 \mathrm{a}$ & $\ldots$ & $143.39, \mathrm{C}$ & $\ldots$ \\
10 & $\ldots$ & $141.05, \mathrm{C}$ & $\ldots$ \\
$\mathrm{C}=\mathrm{O}$ & $\ldots$ & 166.86 & $\ldots$ \\
$\mathrm{NH}_{2}$ & $10.72,6.43, \mathrm{br} \mathrm{s}$ & $\ldots$ & $\ldots$ \\
\hline
\end{tabular}


A<smiles>NC(=O)c1cccc2nc3ccccc3nc12</smiles>

B

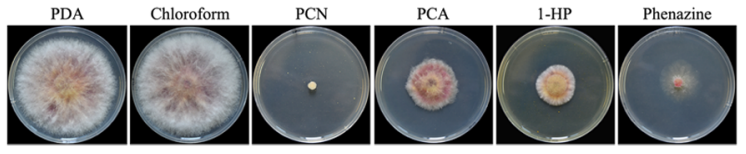

$\mathrm{C}$
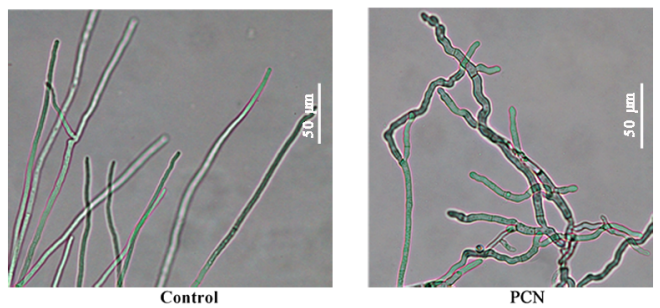

$\mathrm{D}$

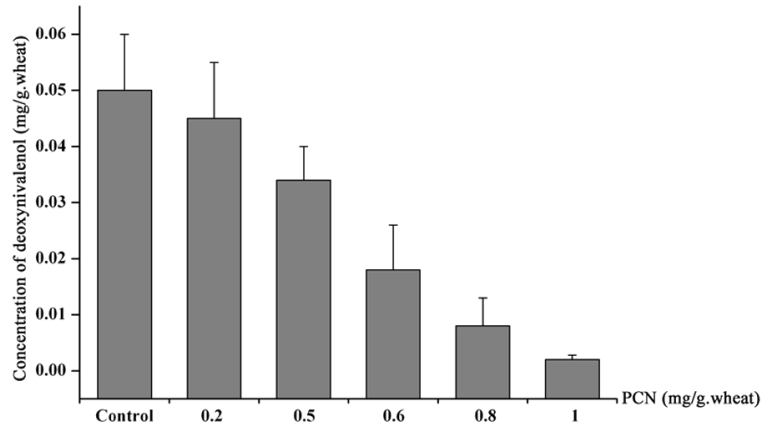

$\mathrm{E}$

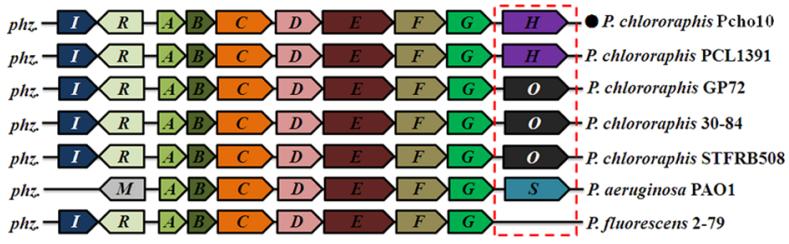

Fig. 4. Characteristics of the antifungal compound phenazine-1-carboxamide and its biosynthesis operon. A, Chemical structure of compound number 1 , phenazine-1-carboxamide ( $\mathrm{PCN})$. B, Antifungal activity of phenazines produced Pseudomonas spp. strains against Fusarium graminearum. F. graminearum PH-1 was inoculated on potato dextrose agar (PDA) plates containing phenazine-1-carboxamide, 1-phenazine carboxylic acid (PCA), 1-hydroxyphenazine (1-HP), or phenazine individually at $35 \mu \mathrm{g} / \mathrm{ml}$. Plates were imaged when mycelial growth on the control plate extended to twothirds of the diameter of the plate. Solvent chloroform was used as a negative control. C, Morphology of mycelia treated with PCN at $20 \mu \mathrm{g} / \mathrm{m}$; after $18 \mathrm{~h}$. Photos was obtained using a Leica TCS SP5 imaging system. The bar represents $50 \mu \mathrm{m}$. D, Deoxynivalenol production of wheat kernels inoculated with $F$. graminearum and supplemented with various amounts of PCN. The experiment was repeated three times. E, Organization of the phenazine biosynthesis gene clusters in several Pseudomonas spp. strains. Genes and their orientations were indicated by arrows. Homologous genes in $P$. chlororaphis PCL1391, GP72, 30-84, and STFRB508; P. aeruginosa PAO1; and $P$. fluorescens 2-79 were indicated by arrows of the same color. Variable phenazine-modifying enzyme loci are labeled with a dashed red frame.
PCA into PCN, enabling this strain to produce both PCA and PCN (8). These results were in agreement with the two pigment compounds produced by Pcho10 (Fig. 2).

$F$. graminearum biocontrol efficacy of Pcho10 under laboratory and field conditions. Under growth chamber conditions, the Pcho10 cell suspension $\left(10^{8} \mathrm{CFU} / \mathrm{ml}\right)$ significantly reduced $F$. graminearum infection of the two tested cultivars (Fig. $5 \mathrm{~A}$ and $\mathrm{B})$. There were no significant differences in efficacy

A

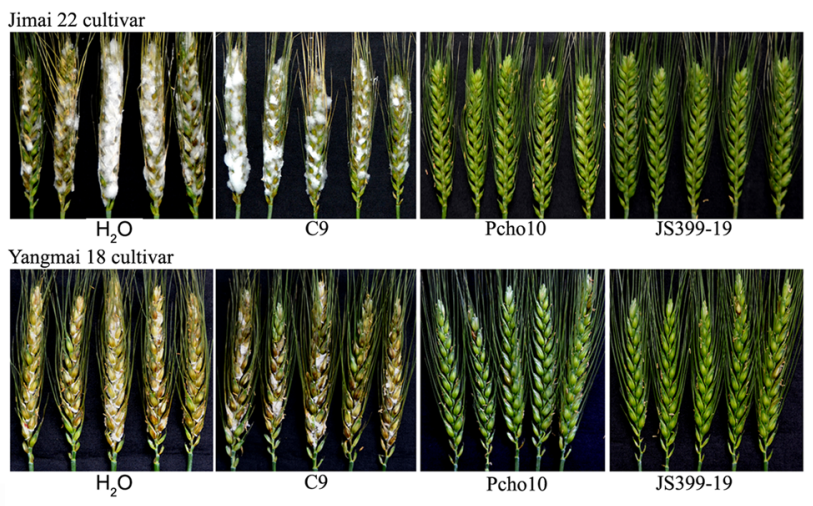

B

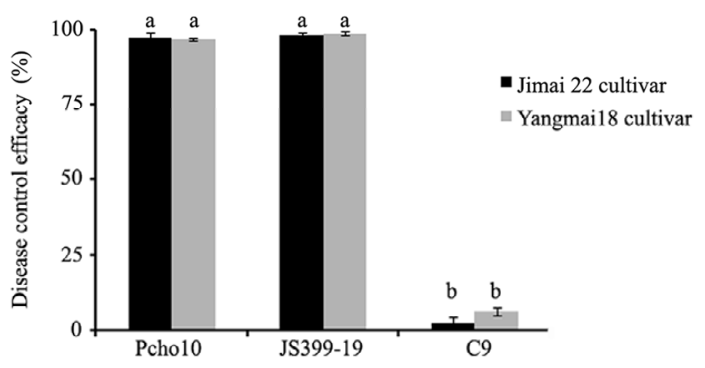

C

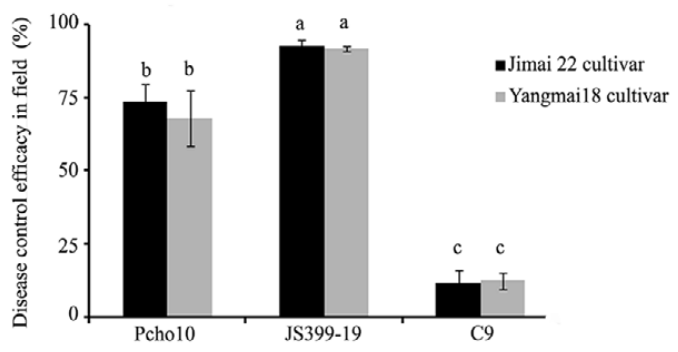

Fig. 5. Effects of a Pcho10 cell suspension (JS399-19) against Fusarium head blight (FHB) on two wheat cultivars ('Jimai 22' and 'Yangmai 18') under laboratory and field conditions. A, Disease severity of different treatments. Photos were obtained at 7 days after inoculation of wheat heads with $\mathrm{Fu}$ sarium graminearum conidia. B, Pcho10 biocontrol efficacy under growth chamber conditions. C, Effect of Pcho10 against FHB on two wheat cultivars (Jimai 22 and Yangmai 18) in field trials. The microorganism C9 and the fungicide JS399-19 served as negative and positive controls, respectively. Columns with the same letters are not significantly different $(P=0.05)$.

TABLE 5. Similarity of the phenazine biosynthesis genes of Pseudomonas chlororaphis Pcho10 and other Pseudomonas spp. ${ }^{\mathrm{a}}$

\begin{tabular}{|c|c|c|c|c|c|c|c|c|c|c|c|}
\hline \multirow[b]{2}{*}{ Strain } & \multirow[b]{2}{*}{ GenBank accession } & \multicolumn{10}{|c|}{ Phenazine biosynthesis genes in Pcho10 (KJ457347) (\%) } \\
\hline & & phzI & $p h z R$ & $p h z A$ & $p h z B$ & $p h z C$ & $p h z D$ & $p h z E$ & $p h z F$ & $p h z G$ & $p h z H$ \\
\hline P. chlororaphis PCL1391 & AF195615 & 99 & 99 & 90 & 90 & 99 & 99 & 99 & 99 & 96 & 97 \\
\hline P. chlororaphis 30-84 & L33724 & 99 & 93 & 86 & 85 & 96 & 96 & 96 & 96 & 95 & $p h z Q$ \\
\hline P. chlororaphis STFRB508 & AB794886 & 95 & 94 & 87 & 86 & 96 & 96 & 96 & 96 & 96 & $p h z Q$ \\
\hline P. fluorescens 2-79 & L48616 & 79 & 86 & 80 & 80 & 89 & 92 & 90 & 90 & 86 & $\mathrm{NA}$ \\
\hline P. aeruginosa $\mathrm{PA} 7$ & CP000744 & NA & NA & 78 & 77 & 77 & 82 & 80 & NA & NA & NA \\
\hline
\end{tabular}

a $\mathrm{NA}=$ not applicable. 
between Pcho10 and the fungicide JS399-19 in the chamber tests. In field trials, the fungicide JS399-19 was highly effective against FHB, which is consistent with previous reports $(6,27)$. The efficacy of Pcho10 was 67 to $73 \%$, whereas the negative control strain C9 exhibited little efficacy against FHB (Fig. 5C). These results indicate that Pcho10 is effective against FHB under both laboratory and field conditions.

Population dynamics of Pcho10 on wheat spikes. The level of Pcho10 populations recovered from wheat spikes in the growth chamber was decreased from $10^{9} \mathrm{CFU} /$ spikes on the first day after inoculation and remained stable for the following 6 days at $10^{8}$ CFU/spikes (Fig. 6A). Pcho10 cells were asymmetrically distributed on the surface of wheat spikes (Fig. 6B). In the field trials, the Pcho10 populations on wheat spikes decreased to $10^{5}$ CFU/spikes on the 25 days after application (Fig. 6C).

\section{DISCUSSION}

The environment serves as a large reservoir for biological control agents. Screening for effective biocontrol agents that match with field conditions has been shown to result in successful biocontrol (21). In this study, the Pcho10 strain was isolated from wheat heads and displayed strong activity against $F$. graminearum under both laboratory and field conditions. Because Pcho10 showed potential as a biocontrol agent for various fungi, it should be applied together with chemical control agents in future field studies. However, we first determined whether Pcho10 cells are resistant to various fungicides by examining the cell density and colony morphology of Pcho10 in KB broth and on agar plates with or without supplementation of tested fungicides (Supplemental Figure 1). Common fungicides for FHB disease management displayed no inhibition against the cell growth of Pcho10. Therefore, Pcho10 application in conjunction with chemical fungicides may yield synergistic activity in the control of FHB. Despite the numerous studies of the activities of Pseudomonas spp. such as $P$. fluorescens, $P$. putida, $P$. aeruginosa, $P$. aureofaciens, and $P$. chlororaphis against various phytopathogenic pathogens, we found for the first time that $P$. chlororaphis subsp. aurantiaca strain Pcho10 has the potential to be developed as a biofungicide for management of FHB.

Phenazines are broad-spectrum, heterocyclic antibiotics produced by various Pseudomonas spp., including the biocontrol strains P. aeruginosa PAO1 (32); P. chlororaphis PCL1391, 30-84, and GP72 (7,22,47); and P. fluorescens 2-79 (33). Bioinformatic comparison of the phzABCDEFG phenazine biosynthetic genes in Pseudomonas spp. strains demonstrated a high degree of conservation $(31,34,38,46)$. In most phenazine-producing strains, the core biosynthetic genes are flanked by one or more accessory genes that encode various terminal-modifying enzymes that result in the production of additional phenazine derivatives. For example, the biocontrol agents $P$. chlororaphis 30-84 and GP72 contain $p h z O$, which encodes a mono-oxygenase, located immediately downstream of the core genes $(13,22)$. PhzO converts PCA to 2-hydroxyphenazine-1-carboxylic acid and 2-hydroxyphenazine $(13,22,47)$. P. chlororaphis PCL1391 and P. aeruginosa PAO1 contain $p h z H$, which encodes a putative transamidase that converts a portion of PCA into PCN, enabling these strains to produce both PCA and PCN (8). Two additional genes in $P$. aeruginosa $\mathrm{PAO} 1-p h z M$, encoding a methyltransferase (43), and $p h z S$, encoding a flavin-containing mono-oxygenase-together are responsible for the conversion of PCA to pyocyanin (19, 32). The presence of these accessory genes encoding modification enzymes for phenazine provides structural diversity to the phenazine-derived molecules and the associated antimicrobial activities. In this study, the $p h z H$ gene was found to be located downstream of the core phenazine biosynthesis genes ( $p h z A$ to $p h z G)$ in Pcho10, indicating that PCA could be converted to PCN by this strain. This was further confirmed by our ESI-MS analysis, which identified the active compound number 1 as PCN. In addition, the specific primers (Table 1) used to amplify the antibiotics biosynthesis genes pyoluteorin, pyrrolnitrin, and 2,4DAPG biosynthesis genes from Pseudomonas spp. (37) did not amplify any fragment from Pcho10. Taken together, these results indicate that Pcho10 produces both PCA and PCN, and that PCN is the major compound responsible for activity against FHB. The antifungal activity and spectrum of Pcho10 and PCN (Table 3; Fig. 4; Supplemental Figure 2) suggested that this strain has potential biocontrol agent for other phytopathogenic fungi, especially $F$. oxysporum and $M$. oryzae.

The application method and timing play significant roles in the success of disease control using biocontrol agents. Most com-

A

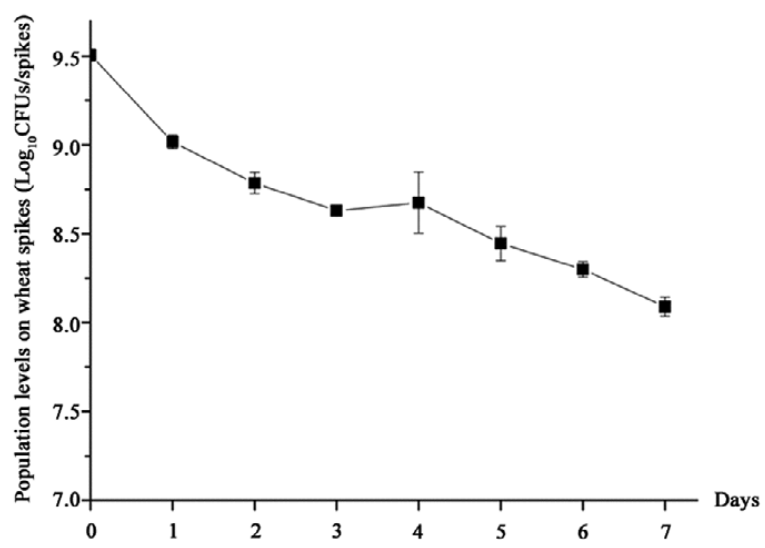

B

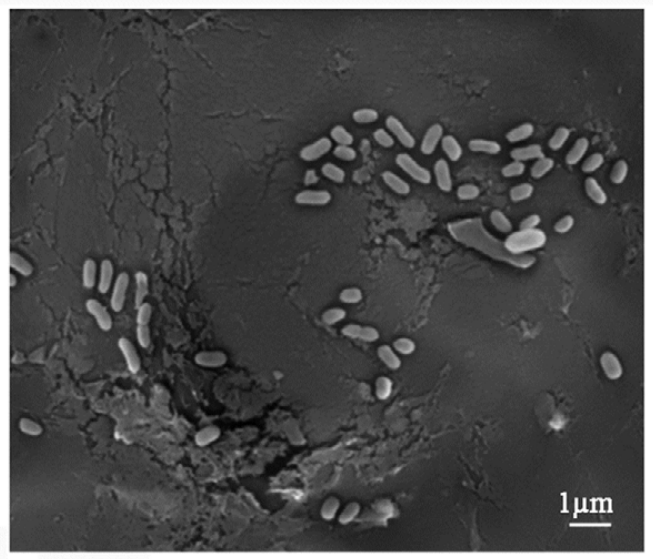

C

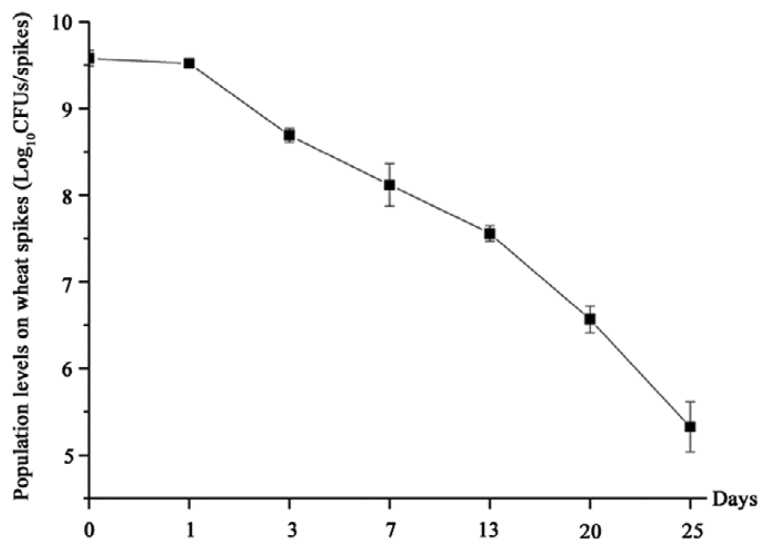

Fig. 6. Population dynamics of Pcho10 on wheat spikes during biocontrol of Fusarium head blight disease. A, Pcho10 population on wheat spikes in the growth chamber. B, Pcho10 colonization patterns on the surface of wheat spikes in the growth chamber. The image was obtained using a Hitachi TM1000 tabletop microscope 7 days after inoculation. The bar represents $1 \mu \mathrm{m}$. C, Pcho10 populations on wheat spikes in the field trials. 
mercial products based on soil bacteria are applied as seed dressings to prevent soilborne diseases, such as Quantum 4000, a commercial product of Bacillus subtilis (10), and Mycolytin and Cedomon, which are based on a $P$. chlororaphis strains $(P$. aurantiaca M-518 and $P$. chlororaphis MA 342, respectively) $(28,40)$. Here, we found that both the Pcho10 suspension and pure PCN showed higher bioactivities against spore germination than against mycelium growth. Furthermore, treatment of wheat heads with a Pcho10 cell suspension before conidial inoculation in both growth chambers and field experiments reduced the incidence of FHB significantly. These results suggest that, in terms of the timing, the Pcho10 should be sprayed before pathogen infection to suppress conidial germination for effective disease control.

Successful colonization and antifungal metabolite (AFM) production on the plant surface or within plant tissues are critical for biocontrol agents to suppress disease development. The Pcho10 population was stable after application in the growth chamber but decreased dramatically in the field (Fig. 6). The survival of biocontrol agents applied in the field is influenced by several factors, especially the ecological fitness of the agents. Several strategies have been reported to improve survival of biocontrol microorganisms in natural environments, such as the use of a formulation with osmoadaptation, nutritional enhancement, and adjuvants to increase the colonization and survival of the biocontrol agent in the phytosphere of rosaceous plants $(2,3,23,48)$. AFM production and release are also influenced by various biotic and abiotic conditions. PCN production is correlated with autoinducer levels affected by diverse agents. In biocontrol strain $P$. chlororaphis PCL1391, PCN production was influenced by carbon, nitrogen, available amino acids, environmental stresses (e.g., salt, temperature, $\mathrm{pH}$, and ions), and biotic stress from soilborne Fusarium spp. fungi (55). Factors affecting the successful application of FHB with Pcho10 in the field may include ultraviolet light, the variable and irregular arrival of pathogen inocula on wheat heads during extended period of heads susceptibility (16,52), and temperature, moisture, and nutrient availability on the wheat phylloplane (49). Thus, to achieve stable biocontrol efficacy toward FHB using Pcho10, suitable formulation and AFM production techniques must be developed.

\section{ACKNOWLEDGMENTS}

The research was supported by the National Key Basic Research and Development Program (2013CB127802), National Science Foundation (31171881), Special Fund for Agro-scientific Research in the Public Interest (Number 201303023), China Agriculture Research System (CARS-3-1-15), and the Fundamental Research Funds for the Central Universities to Y. Chen.

\section{LITERATURE CITED}

1. Barraquio, W. L., Revilla, L., and Ladha, J. K. 1997. Isolation of endophytic diazotrophic bacteria from wetland rice. Plant Soil 194:15-24.

2. Bonaterra, A., Camps, J., and Montesinos, E. 2005. Osmotically induced trehalose and glycine betaine accumulation improves tolerance to desiccation, survival and efficacy of the postharvest biocontrol agent Pantoea agglomerans EPS125. FEMS Microbiol. Lett. 250:1-8.

3. Cabrefiga, J., Frances, J., Montesinos, E., and Bonaterra, A. 2011. Improvement of fitness and efficacy of a fire blight biocontrol agent via nutritional enhancement combined with osmoadaptation. Appl. Environ. Microbiol. 77:3174-3181.

4. Chan, Y.-K., Savard, M. E., Reid, L. M., Cyr, T., McCormick, W. A., and Seguin, C. 2009. Identification of lipopeptide antibiotics of a Bacillus subtilis isolate and their control of Fusarium graminearum diseases in maize and wheat. BioControl 54:567-574.

5. Chen, L. F., Bai, G. H., and Desjardins, A. E. 2000. Recent advances in wheat head scab research in China. National Agricultural Library Internet Publication, U.S. Department of Agriculture, Beltsville, MD. Published online.

6. Chen, Y., Wen-Xiang, W., Ai-Fang, Z., Chun-Yan, G., Ming-Guo, Z., and Tong-Chun, G. 2011. Activity of the fungicide JS399-19 against Fusarium head blight of wheat and the risk of resistance. Agric. Sci. China 10:19061913.

7. Chin-A-Woeng, T. F. C., Bloemberg, G. V., Mulders, I. H. M., Dekkers, L. C., and Lugtenberg, B. J. J. 2000. Root colonization by phenazine-1carboxamide-producing bacterium Pseudomonas chlororaphis PCL1391 is essential for biocontrol of tomato foot and root rot. Mol. Plant-Microbe Interact. 13:1340-1345.

8. Chin-A-Woeng, T. F. C., Thomas-Oates, J. E., Lugtenberg, B. J., and Bloemberg, G. V. 2001. Introduction of the phzH gene of Pseudomonas chlororaphis PCL1391 extends the range of biocontrol ability of phenazine-1-carboxylic acid-producing Pseudomonas spp. strains. Mol. Plant-Microbe Interact. 14:1006-1015.

9. Choudhary, D. K., and Johri, B. N. 2009. Interactions of Bacillus spp. and plants with special reference to induced systemic resistance (ISR). Microbiol. Res. 164:493-513.

10. Connick, W. J. J., Lewis, J. A., and Quimby, P. C. J. 1990. Formulation of biological controls for use in plant pathology. Pages 345-372 in: New Directions in Biological Control. Alternatives for Suppressing Agricultural Pest and Disease. Alan R. Liss, New York.

11. Crane, J. M., Gibson, D. M., Vaughan, R. H., and Bergstrom, G. C. 2013. Iturin levels on wheat spikes linked to biological control of Fusarium head blight by Bacillus amyloliquefaciens. Phytopathology 103:146-155.

12. Dean, R., Van Kan, J. A., Pretorius, Z. A., Hammond-Kosack, K. E., Di Pietro, A., Spanu, P. D., Rudd, J. J., Dickman, M., Kahmann, R., Ellis, J., and Foster, G. D. 2012. The Top 10 fungal pathogens in molecular plant pathology. Mol. Plant Pathol. 13:414-430.

13. Delaney, S. M., Mavrodi, D. V., Bonsall, R. F., and Thomashow, L. S. 2001. phzO, a gene for biosynthesis of 2-hydroxylated phenazine compounds in Pseudomonas aureofaciens 30-84. J. Bacteriol. 183:318-327.

14. D’Mello, J. P. F., Macdonald, A. M. C., Postel, D., Dijksma, W. T. P., Dujardin, A., and Placinta, C. M. 1998. Pesticide use and mycotoxin production in Fusarium and Aspergillus phytopathogens. Eur. J. Plant Pathol. 104:741-751.

15. Dunlap, C. A., Schisler, D. A., Price, N. P., and Vaughn, S. F. 2011. Cyclic lipopeptide profile of three Bacillus subtilis strains; antagonists of Fusarium head blight. J. Microbiol. 49:603-609.

16. Francl, L., Shaner, G., Bergstrom, G., Gilbert, J., Pedersen, W., DillMacky, R., Sweets, L., Corwin, B., Jin, Y., Gallenberg, D., and Wiersma, J. 1999. Daily inoculum levels of Gibberella zeae on wheat spikes. Plant Dis. 83:662-666.

17. Gilbert, J., and Haber, S. 2013. Overview of some recent research developments in Fusarium head blight of wheat. Can. J. Plant Pathol. 35:149-174.

18. Goswami, R. S., and Kistler, H. C. 2004. Heading for disaster: Fusarium graminearum on cereal crops. Mol. Plant Pathol. 5:515-525.

19. Greenhagen, B. T., Shi, K., Robinson, H., Gamage, S., Bera, A. K., Ladner, J. E., and Parsons, J. F. 2008. Crystal structure of the pyocyanin biosynthetic protein PhzS. Biochemistry 47:5281-5289.

20. Henkes, G. J., Jousset, A., Bonkowski, M., Thorpe, M. R., Scheu, S., Lanoue, A., Schurr, U., and Rose, U. S. 2011. Pseudomonas fluorescens CHA0 maintains carbon delivery to Fusarium graminearum-infected roots and prevents reduction in biomass of barley shoots through systemic interactions. J. Exp. Bot. 62:4337-4344.

21. Hofte, M., and Altier, N. 2010. Fluorescent pseudomonads as biocontrol agents for sustainable agricultural systems. Res. Microbiol. 161:464-471.

22. Huang, L., Chen, M. M., Wang, W., Hu, H. B., Peng, H. S., Xu, Y. Q., and Zhang, X. H. 2011. Enhanced production of 2-hydroxyphenazine in Pseudomonas chlororaphis GP72. Appl. Microbiol. Biotechnol. 89:169177.

23. Janisiewicz, W. J., Usall, J. B., and Bors, B. 1992. Nutritional enhancement of biocontrol of blue mold on apples. Phytopathology 82:1364-1370.

24. Jayatilake, G. S., Thornton, M. P., Leonard, A. C., Grimwade, J. E., and Baker, B. J. 1996. Metabolites from an Antarctic sponge-associated bacterium, Pseudomonas aeruginosa. J. Nat. Prod. 59:293-296.

25. Jiang, J., Liu, X., Yin, Y., and Ma, Z. 2011. Involvement of a velvet protein $\mathrm{FgVeA}$ in the regulation of asexual development, lipid and secondary metabolisms and virulence in Fusarium graminearum. PLoS One 6:e28291.

26. Khan, M. R., and Doohan, F. M. 2009. Bacterium-mediated control of Fusarium head blight disease of wheat and barley and associated mycotoxin contamination of grain. Biol. Control 48:42-47.

27. Li, H., Diao, Y., Wang, J., Chen, C., Ni, J., and Zhou, M. 2008. JS399-19, a new fungicide against wheat scab. Crop Prot. 27:90-95.

28. Linser, A., Cazzara, L., and Barbieri, G. 2006. Cedomon (P. chlororaphis MA 342) the first natural seed dressing fungicide for wheat and barley. Giornate Fitopatol. Riccione (RN):27-29.

29. Liu, X., Yin, Y., Wu, J., Jiang, J., and Ma, Z. 2010. Identification and characterization of carbendazim-resistant isolates of Gibberella zeae. Plant Dis. 94:1137-1142. 
30. Liu, Y., Chen, X., Jiang, J., Hamada, M. S., Yin, Y., and Ma, Z. 2013. Detection and dynamics of different carbendazim-resistance conferring beta-tubulin variants of Gibberella zeae collected from infected wheat heads and rice stubble in China. Pest Manage. Sci. 70:1228-1236. doi: $10.1002 / p s .3680$

31. Mavrodi, D. V., Blankenfeldt, W., and Thomashow, L. S. 2006. Phenazine compounds in fluorescent Pseudomonas spp. biosynthesis and regulation. Annu. Rev. Phytopathol. 44:417-445.

32. Mavrodi, D. V., Bonsall, R. F., Delaney, S. M., Soule, M. J., Phillips, G., and Thomashow, L. S. 2001. Functional analysis of genes for biosynthesis of pyocyanin and phenazine-1-carboxamide from Pseudomonas aeruginosa PAO1. J. Bacteriol. 183:6454-6465.

33. Mavrodi, D. V., Ksenzenko, V. N., Bonsall, R. F., Cook, R. J., Boronin, A. M., and Thomashow, L. S. 1998. A seven-gene locus for synthesis of phenazine-1-carboxylic acid by Pseudomonas fluorescens 2-79. J. Bacteriol. 180:2541-1548.

34. Mavrodi, D. V., Peever, T. L., Mavrodi, O. V., Parejko, J. A., Raaijmakers, J. M., Lemanceau, P., Mazurier, S., Heide, L., Blankenfeldt, W., Weller, D. M., and Thomashow, L. S. 2010. Diversity and evolution of the phenazine biosynthesis pathway. Appl. Environ. Microbiol. 76:866-879.

35. McMullen, M., Bergstrom, G., Wolf, E. D., Dill-Macky, R., Hershman, D., Shaner, G., and Sanford, D. V. 2012. A unified effort to fight an enemy of wheat and barley: Fusarium head blight. Plant Dis. 96:1712-1728.

36. McMullen, M., Jones, R., and Gallenberg, D. 1997. Scab of Wheat and Barley: A re-emerging disease of devastating impact. Plant Dis. 81:13401348.

37. McSpadden Gardener, B. B., Mavrodi, D. V., Thomashow, L. S., and Weller, D. M. 2001. A rapid polymerase chain reaction-based assay characterizing rhizosphere populations of 2,4-diacetylphloroglucinolproducing bacteria. Phytopathology 91:44-54.

38. Mentel, M., Ahuja, E. G., Mavrodi, D. V., Breinbauer, R., Thomashow, L. S., and Blankenfeldt, W. 2009. Of two make one: The biosynthesis of phenazines. Chembiochem 10:2295-2304.

39. Moussa, T. A. A., Almaghrabi, O. A., and Abdel-Moneim, T. S. 2013. Biological control of the wheat root rot caused by Fusarium graminearum using some PGPR strains in Saudi Arabia. Ann. Appl. Biol. 163:72-81.

40. Omelyanets, T. G., and Melnik, G. P. 1987. Toxicological evaluation of the microbial preparation mycolytin. Zdravookhr. Turkm. 6:8.

41. Palazzini, J. M., Groenenboom-de Haas, B. H., Torres, A. M., Köhl, J., and Chulze, S. N. 2013. Biocontrol and population dynamics of Fusarium spp. on wheat stubble in Argentina. Plant Pathol. 62:859-866.

42. Parry, D. W., Jenkinson, P., and McLeod, L. 1995. Fusarium ear blight (scab) in small grain cereals. Plant Pathol. 44:207-238.

43. Parsons, J. F., Greenhagen, B. T., Shi, K., Calabrese, K., Robinson, H., and Ladner, J. E. 2007. Structural and functional analysis of the pyocyanin biosynthetic protein PhzM from Pseudomonas aeruginosa. Biochemistry 46:1821-1828.

44. Peix, A., Valverde, A., Rivas, R., Igual, J. M., Ramirez-Bahena, M. H., Mateos, P. F., Santa-Regina, I., Rodriguez-Barrueco, C., Martinez-Molina, E., and Velazquez, E. 2007. Reclassification of Pseudomonas aurantiaca as a synonym of Pseudomonas chlororaphis and proposal of three subspecies, P. chlororaphis subsp. chlororaphis subsp. nov., P. chlororaphis subsp. aureofaciens subsp. nov., comb. nov. and $P$. chlororaphis subsp. aurantiaca subsp. nov., comb. nov. Int. J. Syst. Evol. Microbiol. 57:12861290.

45. Pestka, J. J., and Smolinski, A. T. 2005. Deoxynivalenol: Toxicology and potential effects on humans. J. Toxicol. Environ. Health B Crit. Rev. 8:3969.

46. Pierson, L. S., 3rd, and Pierson, E. A. 2010. Metabolism and function of phenazines in bacteria: Impacts on the behavior of bacteria in the environment and biotechnological processes. Appl. Microbiol. Biotechnol. $86: 1659-1670$

47. Pierson, L. S., 3rd, and Thomashow, L. S. 1992. Cloning and heterologous expression of the phenazine biosynthetic locus from Pseudomonas aureofaciens 30-84. Mol. Plant-Microbe Interact. 5:330-339.

48. Rabindran, R., and Vidhyasekaran, P. 1996. Development of a formulation of Pseudomonas fluorescens PfALR2 for management of rice sheath blight. Crop Prot. 15:715-721.

49. Schisler, D. A., Khan, N. I., Boehm, M. J., and Slininger, P. J. 2002 Greenhouse and field evaluation of biological control of Fusarium head blight on durum wheat. Plant Dis. 86:1350-1356.

50. Shali, A., Ghasemi, S., Ahmadian, G., Ranjbar, G., Dehestani, A., Khalesi, N., Motallebi, E., and Vahed, M. 2012. Bacillus pumilus SG2 chitinases induced and regulated by chitin, show inhibitory activity against Fusarium graminearum and Bipolaris sorokiniana. Phytoparasitica 38:141-147.

51. Steiner, B., Kurz, H., Lemmens, M., and Buerstmayr, H. 2009. Differential gene expression of related wheat lines with contrasting levels of head blight resistance after Fusarium graminearum inoculation. Theor. Appl. Genet. 118:753-764.

52. Tamez-Guerra, P., McGuire, M. R., Behle, R. W., Shasha, B. S., and Wong, L. J. 2000. Assessment of microencapsulated formulations for improved residual activity of Bacillus thuringiensis. J. Econ. Entomol. 93:219-225.

53. Tamura, K., Dudley, J., Nei, M., and Kumar, S. 2007. MEGA4: Molecular Evolutionary Genetics Analysis (MEGA) software version 4.0. Mol. Biol. Evol. 24:1596-1599.

54. Tekauz, A., McCallum, B., and Gilbert, J. 2000. Fusarium head blight of barley in western Canada. Can. J. Plant Pathol. 22:9-16.

55. van Rij, E. T., Wesselink, M., Chin-A-Woeng, T. F. C., Bloemberg, G. V., and Lugtenberg, B. J. J. 2004. Influence of environmental conditions on the production of phenazine-1-carboxamide by Pseudomonas chlororaphis PCL1391. Mol. Plant-Microbe Interact. 17:557-566.

56. Wang, J., Liu, J., Chen, H., and Yao, J. 2007. Characterization of Fusarium graminearum inhibitory lipopeptide from Bacillus subtilis IB. Appl. Microbiol. Biotechnol. 76:889-894.

57. Weisburg, W. G., Barns, S. M., Pelletier, D. A., and Lane, D. J. 1991. 16S ribosomal DNA amplification for phylogenetic study. J. Bacteriol. 173:697-703.

58. Xue, A. G., Voldeng, H. D., Savard, M. E., Fedak, G., Tian, X., and Hsiang, T. 2009. Biological control of Fusarium head blight of wheat with Clonostachys rosea strain ACM941 Can. J. Plant Pathol. 31:169-179.

59. Yin, Y., Liu, X., Li, B., and Ma, Z. 2009. Characterization of stero demethylation inhibitor-resistant isolates of Fusarium asiaticum and F. graminearum collected from wheat in China. Phytopathology 99:487-497. 